Nig. J. Biotech. Vol. 36 (1): 87-93 (June 2019)

ISSN: 01891731

Available online at

http://www.ajol.info/index.php/njb/index

and www.biotechsocietynigeria.org

DOI: https://dx.doi.org/10.4314/njb.v36i1.12

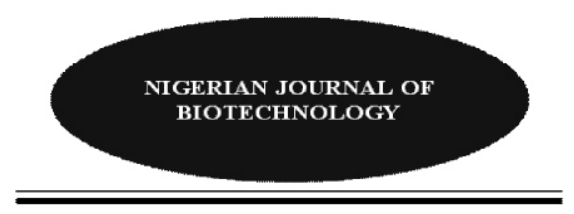

\title{
Effect of fungi on dyes used in making Nigerian tie and dye cloths ('Adire') and shelf-life determination
}

Bankole, P. O., ${ }^{1 *}$ Adekunle, A. A. ${ }^{2}$ and Obidi, O. F. ${ }^{3}$

${ }^{1}$ Department of Pure and Applied Botany, College of Biosciences, Federal

University of Agriculture, Abeokuta, Ogun State, Nigeria

${ }^{2}$ Department of Botany, University of Lagos, Akoka, Lagos State, Nigeria

${ }^{3}$ Department of Microbiology, University of Lagos, Akoka, Lagos State, Nigeria

Copyright resides with the authors in terms of the Creative Commons License 4.0.

(See http://creativecommons.org/licenses/by/4.0/).

Condition of use: The user may copy, distribute, transmit and adapt the work, but must

recognize the authors and the Nigerian Journal of Biotechnology.

\section{Abstract}

Dye quality and fastness properties could only be guaranteed for a finite period of time on shelf. In this study, the shelf-life of natural indigo dye and indigo VAT dye was studied for 360 days. Physico-chemical parameters monitored includes; total viable count, viscosity, pH, specific gravity, absorbance and transmittance from 360 days. Fungi isolated from the dyes on shelf were Achaetomium strumarium, Aspergillus niger, Aspergillus flavus, Duitina rugosa, Penicillium citrinum and Peyronellaea prosopidis. The fungal population count was monitored monthly throughout the shelf-life study period. Multiple linear regression model was used to predict the shelf-life of the dyes from the growth data of the isolated organisms and the physico-chemical parameters. The total fungal viable counts ranged from $1.267 \times 10^{5}-3.213 \times 10^{5}$ spores $\mathrm{ml}^{-1}$ for indigo VAT dye and $1.453 \times 10^{5-}$ $3.347 \times 10^{5}$ spores $\mathrm{ml}^{-1}$ for natural indigo dye over the 12 months study period. The changes in the physico-chemical parameters ranged from $\mathrm{pH} 12.94 \pm 0.00-10.39 \pm 0.01$ and $12.54 \pm 0.00-10.01 \pm 0.01$, specific gravity $1.279 \pm 0.00-1.106 \pm 0.005$ and $1.445 \pm 0.00-1.176 \pm 0.001$, viscosity $1.288 \pm 0.00-1.215 \pm 0.001$ cSt and $1.283 \pm 0.00-$ $1.176 \pm 0.001 \mathrm{cSt}$, optical density $1.627 \pm 0.002-3.323 \pm 0.001$ and $1.705 \pm 0.001-$ $3.315 \pm 0.002$, transmittance $5.573 \pm 0.003-2.652 \pm 0.001$ and $6.124 \pm 0.002-2.108 \pm 0.001$ for indigo VAT dye and natural indigo dye respectively. The percentage dye exhaustion of the shelf-life products determined after the study period peaked at $88 \pm 0.001$ and $90 \pm 0.001 \%$ for indigo VAT dye and natural indigo dye respectively. The shelf-life were found to be 17 months and 10 months for indigo VAT dye and natural indigo dye respectively. The synthetic indigo VAT dye has a higher shelf-life than the natural indigo dye. Imported indigo VAT dye is however recommended based on its longer shelf-life. The results further buttressed the trend where textile dyers in Nigeria and indeed the West African region largely employ imported indigo VAT dye than locally produced natural indigo dye.

Keywords: Shelf-life; Nigerian tie and dye cloths 'Adire'; indigo VAT dye; natural indigo

\section{*Corresponding author: bankolepo@funaab.edu.ng Introduction}

Dyes (either natural or synthetic) can last for a finite or specified period of time if stored properly. Amongst vat dyes, indigo is commonly used for the manufacture of denim. Over time on the shelf, there is an observable change in colour,

\section{Tel. +2348058110550}

quality and occasionally quantity of the dyes which lead to decrease in their economic value (Bankole et al., 2017). The change in colour causes decrease in the quality and shelf-life of the dyes. Efforts geared at controlling the effect of fungi and change in the dyes physico-chemical 


\section{Bankole et al./ Nig. J. Biotech. Vol. 36 Num. 1: 87-93 (June 2019)}

parameters on shelf has not been fully explored. Dyes are versatile chemicals which are employed for several purposes in textiles, leathers, plastics, cosmetics, pulp, paper making, food and pharmaceutical industries, agricultural research, light-harvesting arrays, desizing, scouring, bleaching, finishing, photo-electrochemical cells and hair colouring (Kiran et al., 2009; Aksakal and Ucun, 2010).

Fungi are ubiquitous and thrive pathogenically on most natural and synthetic substrates. The advent of synthetic dyes brought about tremendous decline in the use of natural dyes because the existing natural dyes failed to fulfil-market demands (Singh and Purohit, 2012). Thousands of synthetic dye varieties have since been prepared and used in place of traditional natural dyes (Zollinger, 2003). The limitations to the use of natural dyes in textile dyeing are colour yield, standardization, complexity of dyeing process, limited shades, blending problems and inadequate fastness properties (Sachan and Kapoor, 2005). The use of natural dyes became less pronounced recently with the discovery of reactive textile dyes.

Sporulation of fungi on dyes synergistically with other factors causes decrease in the shelf-life of the dyes used in making Nigerian native cloths. The effect that changes in the physico-chemical parameters (optical density, $\mathrm{pH}$, Specific gravity, Transmittance and Viscosity) brings about in the quality, economic value and shelf-life of the dyes has also not been fully explored. Dyes are well preserved over a long period of time if the manufacturer's instructions are adhered to strictly but their quality and stability depend on the concentration, exposure to moisture and light, $\mathrm{pH}$, heat and microbial infestation. Information on the shelf-life of dyes is quite elusive to researchers, textile practitioners and industry players. The dye decolorization potential of fungi makes significant impact on the quality and shelf-life of the dyes over a period of time. Shelf-life of dyes depends on the degradation mechanism of the dye constituents. Physico-chemical parameters of products are mostly used as variables in shelf-life determination through mathematical modelling (Azanha, 2005). Prediction of shelf-life through mathematical modelling of changes in product characteristics that depletes over time. The study will provide accurate data and information on the effect of fungi and changes in the physicochemical parameters of the dyes used in the Nigerian tie and dye cloths. The shelf-life of synthetic indigo VAT dye was higher than the natural indigo dye produced locally. This study has established that fungi grow on dyes which causes their gradual depletion of colour, economic value, quality and fastness properties on shelf. The findings in this study further established that the sporulation of fungi along with changes in the physicochemical parameters led to a decrease in shelf-life of the dye. This probably might have contributed to the loss of natural indigo dye's widespread utilization, frequency of use, commercial relevance and market value in today's world of tie and dye practice. Hence this present study is to evaluate the effect of fungi on the shelflife of indigo dyes and their exhaustion properties.

\section{Materials and Methods}

\section{Chemicals}

The indigo VAT dye was purchased from DyStar Company, Frankfurt, Germany while natural indigo dye was kindly donated by Nike Arts Gallery, Osogbo, Osun State, Nigeria which is a foremost tie and dye manufacturing. They were collected in sterile airtight plastic can and stoppered before experimental usage.

\section{Description of the indigo dye}

Indigo dye belongs to the VAT class of dyes with Molecular weight: $262.26 \mathrm{~g} \mathrm{~mol}^{-1 ;}$ Molecular formula: $\mathrm{C}_{16} \mathrm{H}_{10} \mathrm{~N}_{2} \mathrm{O}_{2}$ and chemical structure (Figure 1).

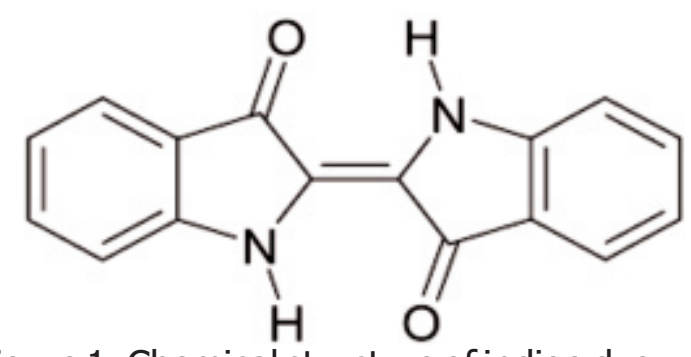

Figure 1: Chemical structure of indigo dye

Isolation and identification of fungi from Indigo VAT and Natural indigo dyes

Aliquots were prepared by seeding $1 \mathrm{ml}$ of the $500 \mathrm{mg} \mathrm{L}^{-1}$ of the concentrations of the dyes in sterilized $10 \mathrm{ml}$ test tubes containing $9 \mathrm{ml}$ of sterile distilled water. The test tubes containing the mixture was shaken for homogenization and the contents were serially diluted in ten (10) folds. $1 \mathrm{ml}$ aliquots of $10^{-2}, 10^{-6}$ and $10^{-8}$ (representing low to medium and high dilutions) were then 


\section{Bankole et al./ Nig. J. Biotech. Vol. 36 Num. 1: 87-93 (June 2019)}

plated on already prepared plates containing sterile solidified potato dextrose agar medium which were then incubated at room temperature $\left(30^{\circ} \mathrm{C}\right)$ with daily inspections for growth of fungal colonies and re-isolation till a pure isolate is obtained. This was done repeatedly on a monthly basis for the 12 months period of shelf-life study, estimation and prediction. Neubauer Improved Counting Chamber system (Haemocytometer) was used in taking monthly measurement of fungi growth on the dyes (APHA, 2005). The 23S ribosomal ribonucleic acid (rRNA) analyses were contracted out to Laragen Incorporated, USA. Basic Local Alignment Search Tool (BLAST) query was conducted with previous submissions obtainable in the GenBank database. Submission of the molecular sequence data was done at the GenBank using the BankIt tool (Bankole et al., 2017).

FTIR characterization of natural indigo dyestuff and indigo VAT dye at day 0 and day 360.

The method of Dolores et al. (2008) was adopted. UV-visible spectrum analysis of the Natural Indigo dye was carried out immediately after production using Shimadzu UV spectrophotometer (Shimadzu UV 1600, Japan) with dilution and changes in its absorption spectrum of the dyes in the visible range (200-800 nm) were recorded. Fourier Transform Infrared Spectroscopy (FTIR) spectrum of natural indigo dyestuff and indigo VAT dye was carried out using FTIR model800 spectrophotometer (Shimadzu, Japan) (Olukanni et al., 2010). The samples (control at day 0 and 360 days metabolites) were previously mixed with Infrared (IR) grade Potassium Bromide $(\mathrm{KBr})$ in the ratio $10: 90$, fixed in sample holder before scans were done.

\section{PHYSICO-CHEMICAL PARAMETERS MONITORING} $\mathrm{pH}$

The method of Obidi et al. (2010) was used. The $\mathrm{pH}$ of the dyes was measured and monitored with the aid of Hanna $\mathrm{pH}$ meter (Hanna pH Meter 290, Hanna Instruments, Rhode Island, USA). The meter was calibrated and standardized with sterile distilled water $(\mathrm{pH}$ 7.00) and phosphate buffer ( $\mathrm{pH} 4.00)$.

\section{Kinematic Viscosity}

Kinematic viscosity of the various prepared dye concentrations was determined using a glass capillary tubular viscometer (Capirograph Toyoseikl Seisaku-Sho Ltd., Ibaraki, Japan) as described by Rammohan and Yassen (2003) and by following Japanese Pharmacopeia specifications. The dye sample was allowed to flow through an outlet tube (measuring tube which is narrowed into a capillary tube above the outlet). Two annular reference marks on the measuring tubes were used. The time (in seconds) it took each sample meniscus to drop from the upper to the lower reference mark was taken manually with a stop-watch and recorded accordingly in Centistokes (cSt). The viscosity was then calculated by multiplying the measured time by the viscometer calibration factor $\mathrm{CF}$, 0.0009418 at room temperature $\left(30^{\circ} \mathrm{C}\right)$.

Viscosity $=$ Time $($ in seconds $) \times C F$

Where $\mathrm{CF}=$ Viscometer Calibration Factor $=0.0009418$.

\section{Specific gravity}

Specific gravity was determined using a pycnometer (Ohwoavworhua and Adelakun, 2005) with slight modification and in accordance with Japanese Pharmacopeia specifications. A sterile dried and emptied pycnometer of $50 \mathrm{ml}$ capacity was weighed and the weight recorded as $W_{1}$. The pycnometer was then filled with water and weighed. The weight was recorded as $W_{2}$. From the 1 litre formulations of different dyes sample, $50 \mathrm{ml}$ was transferred into the pycnometer. The pycnometer and its dye content were weighed and the weight was recorded as $\mathrm{W}_{3}$. The pycnometer was shaken many times to allow all trapped air within to be expelled when filled with either the dye sample or sterile distilled water. Specific gravity was then calculated and recorded in triplicates using the formula:

\section{Spore count}

$\dot{S} G=\frac{W 2-W 1}{W 2-W 1}$

The method of Gupta (2010) was used to count the spores on observation of full growth within 48-72 hours of fungal cultures. The spore suspension was prepared by adding $5 \mathrm{ml}$ of distilled water to each of the plates (in triplicates) and shaken well so that the spores were dislodged and homogenized. Spore lumps were dislodged using a sterile scalpel. $1 \mathrm{ml}$ was then taken with the use of a sterile pipette and mixed with $2 \%$ Trypan blue in a sterile test tube. The coverslip was then fixed on the Neubauer Improved Counting Chamber system (Superior Marienfeld Laboratory Glassware, Germany). Ten microliters $(10 \mu \mathrm{l})$ aliquot of the spore suspension mixture with Trypan blue was placed beside the coverslip of the chamber and allowed to flow by capillary action for 2 minutes until the stop of flow. The Trypan blue added was to differentiate and count only the viable cells in the suspension. The chamber was then placed under a light microscope for enumeration of the number of 


\section{Bankole et al./ Nig. J. Biotech. Vol. 36 Num. 1: 87-93 (June 2019)}

spores under $\times 10$ objective magnification and the numbers of spores in 5 squares were counted. The spore count was monitored in each of the conical flasks of different concentrations (in triplicates) set of shelf-life determination and recorded accordingly. This was done on monthly basis for the 12 months period of shelf-life study. The number of spores $\mathrm{ml}^{-1}$ was calculated using the formula:

\section{Absorbance and Transmittance}

The method of Obidi et al. (2010) was employed. The absorbance was monitored and recorded at a wavelength of $600 \mathrm{~nm}$ with a Spectrophotometer (UNICO 1200 Series, United Products and Instruments Incorporated, USA). The spectrophotometer was standardized by adjusting it to read $100 \%$ light transmittance with $5 \mathrm{ml}$ distilled water at a wavelength pre-set at 600 $\mathrm{nm}$. Five $(5 \mathrm{ml})$ of diluted dye samples of different concentrations were poured in the cuvette and then placed in the spectrophotometer. The top scale readings represented the absorbance taken on a monthly basis. The absorbance and transmittance for each of the dye concentrations under shelf-life study was done in triplicates.

\section{SHELF-LIFESTUDY}

Multiple linear regression model of Bankole et al., 2017 was employed in the shelf-life study with slight modifications. $500 \mathrm{mg} \mathrm{L}^{-1}$ concentrations each of natural indigo dye and indigo VAT dye solutions were prepared and stocked in twelve (12) different well corked, airtight Erlenmeyer flasks for each of the dye formulations. The formulations of each of the concentration of the dyes were done in triplicates. Physico-chemical parameters (Specific gravity, Transmittance, Absorbance, $\mathrm{pH}$ and Viscosity) and spore count were then observed, monitored and recorded (in triplicates) in each flask on a monthly basis for twelve (12) months.

$$
\begin{aligned}
& Y i=ß 0+ß 1 X 1+\beta 2 X 2+\beta 3 X 3+\beta 4 X 4+ \\
& ß 5 X 5+\beta 6 X 6+U T
\end{aligned}
$$

\section{Eqn. 1}

Where $\boldsymbol{B}_{\mathbf{0}}$ is the regression intercept, $\boldsymbol{B}_{\mathbf{1}}-\boldsymbol{B}_{6}$ are regression parameter estimates (at $0-360$ days)

$\mathbf{X}_{\mathbf{1}}-\mathbf{X}_{\mathbf{6}}$ (Specific gravity, Transmittance, Absorbance, $\mathrm{pH}$ and Viscosity) are the regression coefficients of the dye under shelf-life study, Yi (the Dependent Variable) is the time (Days), $\mathbf{U}_{\mathbf{T}}$ is the error term.

$Y_{i}=\beta_{0}+\beta_{1}$ (Absorbance) $+\beta_{2}(p H)+\beta_{3}$ (Specific gravity $)+\beta_{4}$ (Spore count) $+\beta_{5}$ (Transmittance $)+$ $\beta_{6}\left(\mathrm{~V}\right.$ is c o s it y ) $+\mathrm{U}_{\mathrm{T}}$ Eqn. 2
DETERMINATION OF DYE PERCENTAGE EXHAUSTION

Hussain et al (2004) method was used in the determination of the dye percentage exhaustion of cotton fabric (E \%) and calculated thus:

$$
\% \text { Dye Exhaustion }=\frac{A_{0}-A_{t} \times 100}{A_{o}}
$$

where $A_{0}=$ Absorbance taken before the dyeing process at maximum wavelength $\left(\lambda_{\max }=620 \mathrm{~nm}\right)$, $A_{t}=$ Absorbance taken during the dyeing process \{at time ( $t=20,40,60,80,100$ and 120 minutes)\}. The dyeing of cotton fabric and dye exhaustion percentage was carried using the control dye on day 0 and the 360 days shelf-life product of each of the dyes.

FASTNESS PROPERTIES ASSESSMENT OF THE DYES AND THEIR SHELF-LIFE PRODUCTS

Fastness to washing and rubbing

This was done using the method of Sahoo et al. (2012). The dimension of the dyed fabric was $5 \mathrm{~cm} \mathrm{X} 4 \mathrm{~cm}$. Each dyed piece was placed between two pieces of undyed cotton and nylon fabrics of the same dimension. Stitching was done around the edges to make a composite specimen. Both fabrics were rubbed by hand vigorously against one another. The specimen was later withdrawn, rinsed and air-dried. Greyscale was used in assessing the change in colour and the staining of the adjacent undyed cloth.

\section{Fastness to light}

The dyed fabrics were cut into strips. The strips were later mounted on a black cardboard paper. This was achieved using the method of Haruna et al. (2013). The portions (half) portions of the fabric strips were covered to block illumination to that portion. The specimens were exposed to natural sunlight and fluorescent lamp light for 14 days. The strips were later removed. Greyscale was deployed in the assessment of fading of the dyed fabric strips.

\section{Fastness to perspiration}

Acidic and alkaline perspiration solutions were prepared to assess the fastness properties. Dyed and undyed fabric strips were immersed separately in alkaline and acidic solutions using liquor ratio of 20:1. The specimens were left in the solutions for 30 minutes at room temperature after which the specimens were brought out, drained and placed in between two glass slides for four hours. They were later dried upon removal. Geometric greyscale was used in assessing the colour change of the dyed fabrics and degree of staining of the adjacent white fabrics. This was achieved using the method of Haruna et al. (2013). 
Bankole et al./ Nig. J. Biotech. Vol. 36 Num. 1: 87-93 (June 2019)

\section{Results and Discussion}

Phenotypic and molecular characterization of the isolates

Five isolates were obtained from both dyes during the shelf-life study period (Table 1 ). The isolates were documented in the GenBank with Accession Numbers

Table 1: Fungi isolated during the shelf-life study period

Isolates Achaetomium Aspergillus

Strumarium flavus

Dye

Indigo VAT

Natural Indigo

$+=$ Present

FTIR CHARACTERIZATION OF THE DYES (CONTROL) AND THEIR 360 DAYS METABOLITE

In the 360 days shelf-life metabolite (Figure 2), it could be observed vividly that the broad peak at $3443.06 \mathrm{~cm}^{-1}$ indicated the formation of more secondary alcohol molecules. It is also obvious that there is the formation of carboxylic acids being represented by sharp absorbance peaks at $1641.48 \mathrm{~cm}^{-1}$ and 1685.54 $\mathrm{cm}^{-1}$. On further observation of the IR spectra of both the control and 360 days shelf life metabolite of the Indigo VAT dye, it showed clearly that there has been a removal of the basic functional groups from 6 peaks to 4 peaks and from 11 peaks to 10 peaks in all.

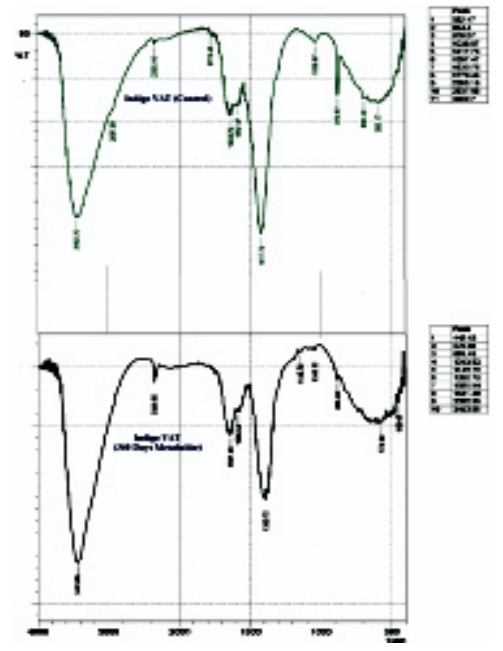

Figure 2: FT-IR Characterization of the Indigo VAT Dye (Control) and 360 Days metabolite

In the 360 days shelf-life metabolite (Figure 3), it could be observed vividly that the broad peak at $3444.98 \mathrm{~cm}^{-1}$ indicated the formation of more secondary alcohol molecules, The corresponding carbonyl group which depicted in the control (C-O stretching) the primary and secondary alcohol functional groups by the sharp absorbance at $1072.46 \mathrm{~cm}^{-1}$ and $1126.47 \mathrm{~cm}^{-1}$ respectively has been removed. On further observation of the IR spectra of both the Control and 360 days shelf-life metabolite of the Natural indigo dye, it showed clearly that there has been a removal of the basic functional groups from 5 peaks to 4 peaks and from 22 peaks to 9 peaks in all.
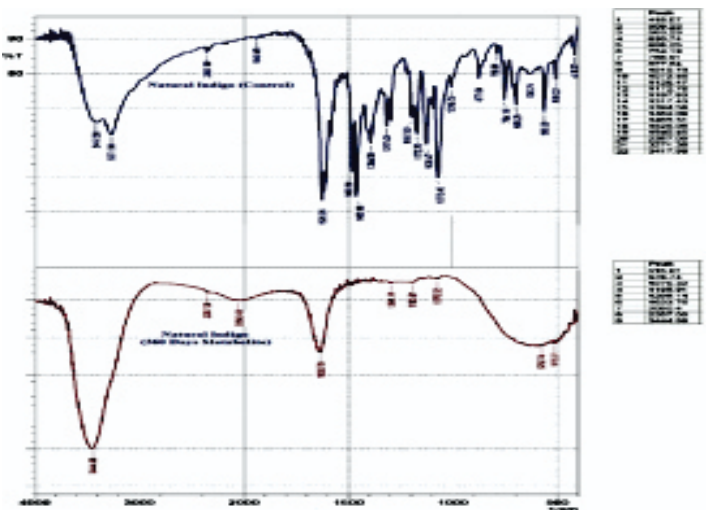

Figure 3: FT-IR Characterization of the Natural Indigo dye (Control) and 360 Days metabolite 
PHYSICO-CHEMICAL PARAMETERSMONITORING

The total fungal viable counts were $1.267 \times 10^{5}-3.213 \times 10^{5}$ spores $\mathrm{ml}^{-1}$ for indigo VAT

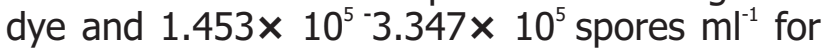
natural indigo dye. The changes in the physicochemical parameters ranged from $\mathrm{pH}$ $12.94 \pm 0.00-10.39 \pm 0.01$ and $12.54 \pm 0.00-$ $10.01 \pm 0.01$, specific gravity $1.279 \pm 0.00$ $1.106 \pm 0.005$ and $1.445 \pm 0.00-1.176 \pm 0.001$, viscosity $1.288 \pm 0.00-1.215 \pm 0.001$ cSt and $1.283 \pm 0.00-1.176 \pm 0.001 \mathrm{cSt}$, absorbance $0.545 \pm 0.002-0.956 \pm 0.001$ and $0.705 \pm 0.001-$ $0.989 \pm 0.002$, transmittance $1.573 \pm 0.002-$ $0.558 \pm 0.02$ and $1.673 \pm 0.02-1.165 \pm 0.02$ for indigo VAT dye and natural indigo dye respectively. It is also noteworthy that the basicity of all the dyes increases with increasing concentration. A remarkable steady decrease was observed in the specific gravity of all the dye solutions studied and across different concentrations of the dyes. The decrease in specific gravity is attributable to the activities of fungi and changes in other physico-chemical parameters which cause the disintegration of intermolecular forces responsible for the covalent bonds and cohesion of the dye molecules. This in turn causes reduction in the weight of the

Table 3. Percentage dye exhaustion of the indigo VAT dye and natural indigo dye and the shelf-life product.

\begin{tabular}{ccccc} 
& \multicolumn{2}{c}{ Indigo VAT dye } & \multicolumn{2}{c}{$\begin{array}{c}\text { Natural indigo Dye } \\
(\%)\end{array}$} \\
Time (hr) & Control & Test & Control & Test \\
\hline 20 & $22 \pm 0.12$ & $25 \pm 0.27$ & $43 \pm 0.55$ & $55 \pm 0.11$ \\
40 & $63 \pm 0.57$ & $65 \pm 0.32$ & $62 \pm 0.17$ & $63 \pm 0.23$ \\
60 & $70 \pm 0.19$ & $72 \pm 0.78$ & $75 \pm 0.25$ & $78 \pm 0.13$ \\
80 & $75 \pm 0.52$ & $80 \pm 0.15$ & $83 \pm 0.31$ & $85 \pm 0.72$ \\
100 & $80 \pm 0.17$ & $86 \pm 0.67$ & $88 \pm 0.57$ & $90 \pm 0.32$ \\
120 & $83 \pm 0.14$ & $88 \pm 0.29$ & $61 \pm 0.42$ & $63 \pm 0.22$ \\
\hline
\end{tabular}

It was evident from the result of the assessments presented on Table 4 that on the cotton fabric, the control dye exhibited good to excellent fastness test to washing, rubbing, light and perspiration but very poor to poor to fair fastness was recorded on dyeing the cotton fabric with the shelf-life product.

Table 4. Fastness properties assessment of the dyes.

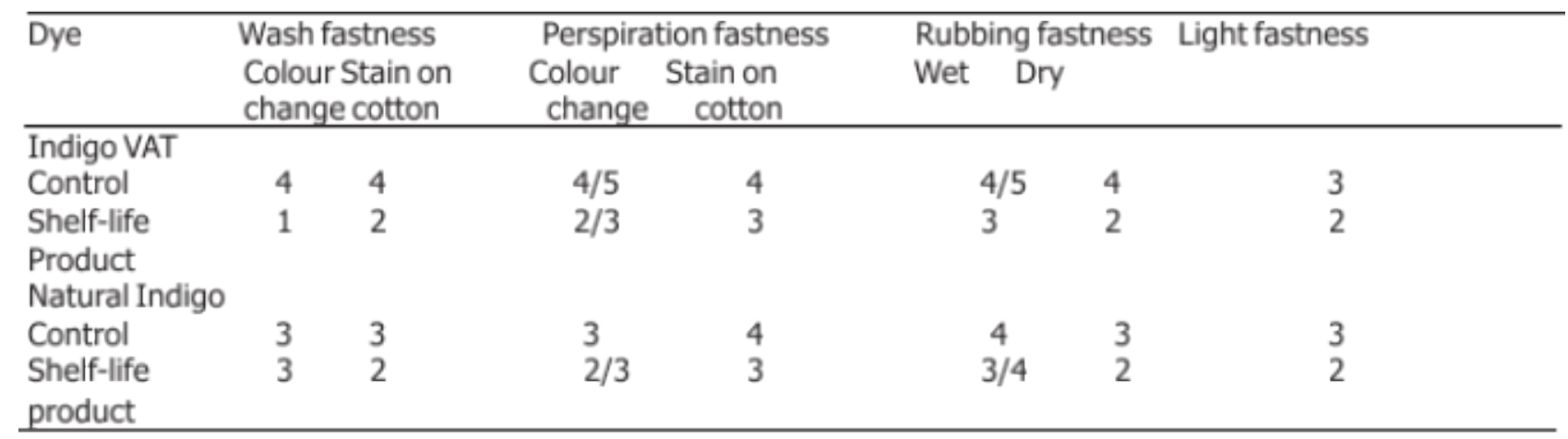

Greyscale ratings for washing fastness test: 5-Excellent; 4-Good, 3- Fair 2-Poor, 1-Very poor

Greyscale ratings for staining: 1-Much change, 2-Considerable change, 3-Noticeable change, 4-Slight change and 5-Negligible change

Greyscale ratings for light fastness test: 1 - very poor; 2- poor; 3- moderate; 4- fairly good; 5- good; 6very good; 7-excellent; 8-outstanding 


\section{Bankole et al./ Nig. J. Biotech. Vol. 36 Num. 1: 87-93 (June 2019)}

\section{Conclusion}

Changes occur in quality and fastness properties of the dyes, indigo VAT (synthetic) and natural indigo on shelf as a result of infestation by microbes (fungi), light penetration and other environmental conditions. These changes which seems unnoticeable physically affects the dye fastness, light fastness, wash fastness, rubbing fastness and perspiration fastness. Hence, this study was designed to scientifically predict a determinate shelf-life of dyes used in Nigerian tie and dye cloths ('Adire'). This would further provide information and educate textile dye practitioners on the length of time the quality of the dyes can be guaranteed on shelf.

\section{References}

Aksakal, O. and Ucun, H. (2010). Equilibrium, kinetic and thermodynamic studies of the biosorption of textile dye (Reactive Red 195) by Pinus sylvestris L. J. Hazard. Mater. 181 (3): 666672.

APHA (2005). Standard Methods for the Examination of Water and Wastewater, 21st ed.American Public Health Association, Washington, DC.

Ali, N., Hameed, A. and Ahmed, S. (2010). Role of brown-rot fungi in the bio-removal of azo dyes under different conditions. Brazilian J. Microbiol. 41 (4): 78-85.

Almalik, O., Nijhuis, M. B. and Van den Heuvel, E. R. (2014). Combined statistical analyses for longterm stability data with multiple storage conditions: a simulation study. J. Biopharm. Stat. 24 (3): 493-506.

Azanha, A. B. (2005). Use of mathematical models for estimating the shelf-life of cornflakes in flexible packaging. Packaging Technol. Sci. 18 (4): 161-222.

Bankole, P. O., Adekunle, A. A. and Obidi, O. F. (2017). Mycodecolorization of Reactive Red HE7B dye by Achaetomium strumarium and Aspergillus flavus and shelf-life determination. Cogent Environ. Sci. 3 (1): 1278646.

Dolores, J. Y., María, T. D., Ivan, L. V., Antonio, F. B., Sofia, V. and Laura, F. (2008). Characterization of colouring compounds in Annatto (Bixa orellana L.) used in historic textiles by means of UV-VIS spectrophotometry and FT-IR spectroscopy. Arché. Publicación Del Instituto Universitario De Restauración Del Patrimonio De La Upv. 3: 153158.

Gupta, V. K., Misra, A. K. and Gaur, R. K. (2010).
Growth characteristics of Fusarium sp. causing wilt disease in Psidium guajava in India. J. Plant Prot. Res. 50 (4): 452-462.

Haruna, M., Abdulmumini, A., Folashade, M. O., Bishir, U. and Hamza, A. (2013). Studies on the dyeing of wool and nylon fabrics with some acid dyes. J. Appl. Chem. 5 (1): 11-17.

Hussain, T., F. Akhtar, Inam-ul-Haq, I. Toqeer and H. Farooq. (2004). Usability of Aqueous Solutions of Commercial Reactive Dye for Gamma Dosimetry. Acad. Res. Int. 5(1): 32-36.

Kiran, I., Ilhan, S., Caner, N., Iscen, C. F. and Yildiz, Z. (2009). Biosorption properties of dried Neurospora crassa for the removal of Burazol Blue ED dye. Desalination 249 (1): 273-278.

Loukidou, M. X., Karapantsios, T. D., Zouboulis, A. I. and Matis, K. A. (2004). Diffusion kinetic study of cadmium (II) biosorption by Aeromonas caviae. Technol. Biotechnol. 79: 711-719.

Obidi, O. F., Nwachukwu, S. C., Aboaba, O. O. and Nwalor, J. U. (2010). Estimation of shelf-life for Water-based Paints Using Regression Methods. J. Ame. Sci 6 (4): 123-127.

Ohwoavworhua, F. O. and Adelakun, T. A. (2005). Phosphoric acid-mediated depolymerization and decrystallization of cellulose obtained from corn cob: preparation of low crystallinity cellulose and some physicochemical properties. Trop. J. Pharma. Res. 4 (2): 509-516.

Rammohan, R. M. V. and Yassen, M. (2003). Determination of intrinsic viscosity by single specific viscosity measurements. J. Appl. Polymer Sci. 31 (8): 2501-2508.

Sachan, K. and Kapoor, V. P. (2007). Optimization of Extraction and Dyeing Conditions for Traditional Turmeric Dye. Int. J. Textile Res. 6 (2): 270-278.

Sahoo, T., Bhattacharya, G., Das, P. and Dash, S. K. (2012). Colour intensity, fastness and antimicrobial characteristics of silk fabric dyed with Mahua Bark. Uni. J. Environ. Res. Technol. 2 (6): 591-600.

Singh, S. V. and Purohit, M. C. (2012). Applications of Eco-Friendly Natural Dye on Wool Fibers Using Combination of Natural and Chemical Mordants. Uni. J. Environ. Res. Technol. 2 (2): 4855

Zollinger, H. (2003). Colour chemistry: Synthesis, Properties and Applications of Organic Dyes and Pigments. Weinheim-Wiley VCH publishers, Berlin. pp. 95 